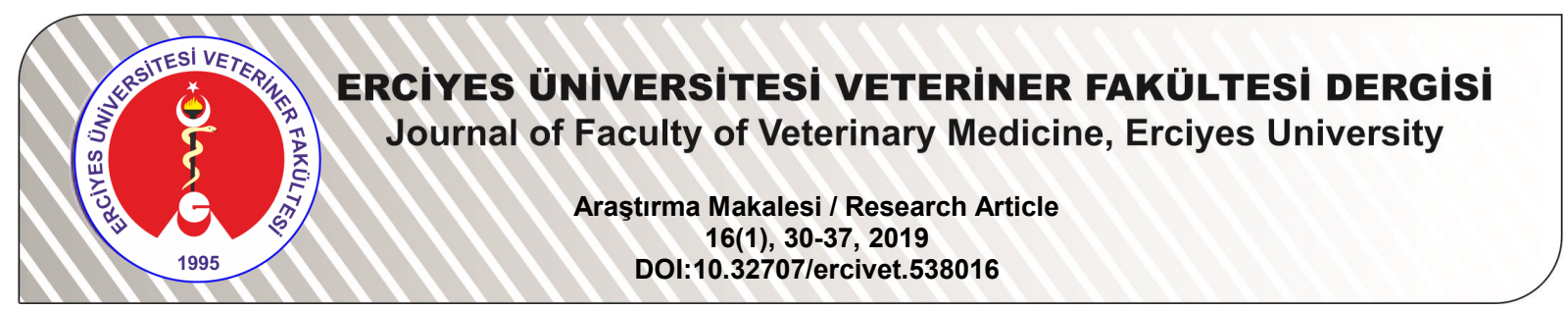

\title{
Rat Epididimal Spermasının Kısa Süreli Saklanmasında Farklı Sıcaklık Dereceleri ve Karnitinin
} Etkileri* $^{*}$

\author{
Mustafa YEŞIL ${ }^{1}$, Serpil SARIÖZKAN² \\ ${ }^{1}$ Çamardı İlçe Tarım ve Hayvancılık Müdürlüğü, Niğde-TÜRKiYE \\ ${ }^{2}$ Erciyes Üniversitesi, Veteriner Fakültesi Dölerme Suni Tohumlama ve Androloji Anabilim Dalı, Kayseri-TÜRKIYE
}

\begin{abstract}
*Sorumlu Yazar: Prof. Dr. Serpil SARIÖZKAN; E-mail: serpilsariozkan@erciyes.edu.tr; ORCID: 0000-0001-5224-2341
Atıf yapmak için: Yeşil M, Sarı̈̈zkan S. Rat epididimal spermasının kısa süreli saklanmasında farklı sıcaklık dereceleri ve karnitinin etkileri. Erciyes Üniv Vet Fak Derg 2019; 16(1): 36-43.
\end{abstract}

Özet: Bu çalışmanın amacı, kısa süreli saklanan (0., 6., 12., 24. ve 48. saat) rat epididimal spermasında farklı saklama derecelerinin $\left(4^{\circ} \mathrm{C}\right.$ ve $\left.37^{\circ} \mathrm{C}\right)$ ve karnitinin spermatolojik parametreler üzerine etkisini araştırmaktır. Araştırmada sperma donörü olarak 10 adet 8-10 haftalık yaş ve 200-250 g ağırlıklarında Wistar-Albino erişkin rat kullanıldı. Epididimisler anestezi altındaki ratlardan cerrahi teknikle alındı. Epididimal sperma numuneleri önce 4 ayrı gruba ayrıldı, numuneler Tris (T) ve Tris $+2 \mathrm{mM}$ karnitin (TC) ile sulandırıldı. Ardından sulandırılan sperma numuneleri $4{ }^{\circ} \mathrm{C}(\mathrm{T}-\mathrm{TC})$ ve $37^{\circ} \mathrm{C}$ (T - TC) de 48 saat süreyle kısa süreli saklandı. Saklama süresinin ardından motilite ve anormal spermatozoa oranı analiz edildi. Uygulama $10 \mathrm{kez}$ tekrar edildi. Çalışmanın sonucunda, tüm deneysel gruplarda 48. saat sonunda anormal spermatozoa oranında artış ve motilite oranında düşme saptandı. Her iki sıcaklık derecesinde motilite ve spermatozoa morfolojik yapısının karnitin katılan gruplarda (TC) daha iyi korunduğu belirlendi. Sonuç olarak, $4{ }^{\circ} \mathrm{C}$ deki motilite oranı $37^{\circ} \mathrm{C}$ ye kıyasla daha yüksek ve anormal spermatozoa oranı ise daha düşük bulundu.

Anahtar kelimeler: Epididimal sperma, karnitin, kısa süreli saklama, rat, spermatolojik parametreler

The Effect of Different Temperature and Carnitine on Liquid Storage of Rat Epididymal Semen

Summary: The aim of this study was to investigate the effects of different storage temperatures $\left(4{ }^{\circ} \mathrm{C}\right.$ and $\left.37^{\circ} \mathrm{C}\right)$ and carnitine on spermatological parameters in liquid stored $(0,6,12,24$ and $48 \mathrm{~h}$ ) rat epididmal semen. In the study, 10 Wistar-Albino rats aged 8-10 weeks and weighing 200-250 g were used as semen. Epididymides of the rats were removed by surgical technique under anaesthesia. Firstly, epididymal semen samples were divided into four groups and samples were diluted with Tris (T) and Tris $+2 \mathrm{mM}$ carnitine (TC). Then diluted semen samples stored in liquid up to $48 \mathrm{~h}$ at $4{ }^{\circ} \mathrm{C}(\mathrm{T}-\mathrm{TC})$ and $37^{\circ} \mathrm{C}(\mathrm{T}-\mathrm{TC})$. After the storage time, the percentage of motility and abnormal spermatozoa were analyzed. Applications were replicated ten times. In the study it was observed while the percentage of abnormal spermatozoa increased, the percentage of motility decreased at the end of the $48 \mathrm{~h}$ in all experimental groups. At both temperatures, it was determined that motility and morphologic structure of spermatozoa were better protected in carnitine supplemented groups (TC). In conclusion, the percentage of motility at $4{ }^{\circ} \mathrm{C}$ were higher and the percentage of abnormal spermatozoa were lower than at $37^{\circ} \mathrm{C}$.

Key words: Carnitine, epididymal semen, liquid storage, rat, spermatological parameters

\section{Giriş}

Spermanın soğutularak kısa süreli ve dondurularak uzun süreli saklanması spermatozoanın canlılığının korunması amacıyla pek çok türün spermasında uygulanmaktadır. Çiftlik hayvanlarında ve evcil hayvanlarda spermanın dondurularak saklanması ve bu dondurulmuş spermanın suni tohumlama uygulamalarında kullanılması üstün genetik kapasiteye sahip neslin devamını sağlamaktadır. Dondurma tekniğinin kullanım alanlarının oldukça çeşitli ve geniş olması evcil olmayan hayvanlarda örneğin rodentlerde de kullanımını da sağlamaktadır $(28,44)$. Reprodüktif materyallerin dondurularak saklanması hayvan yetiştirme programları, insan infertilite uygulamaları ve biyome-

\begin{tabular}{ll}
\hline Geliş Tarihi/Submission Date & $: 20.03 .2018$ \\
Kabul Tarihi/Accepted Date & $: 12.06 .2018$
\end{tabular}

*Bu çalışma aynı başlıklı Yüksek Lisans tezinden özetlenmiştir. dikal araştırmalara da fayda sağlamaktadır (17). Biyomedikal çalışmalarda laboratuvar hayvanları sıklıkla kullanılmaktadır. Fareler ve ratlar biyomedikal çaIışmaların \%97 sini oluşturmaktadır $(2,27)$. Fare ve ratların doğal yolla üretilmeleri ve barındırılmalarının kolay olmasına rağmen, genetik olarak modifiye edilmiş ırkların üretilmeleri ve transportu oldukça maliyetli ve zordur (25). Bu zorluk, üretilmelerinde doğal yolun kullanılmasına yol açmakla birlikte spermanın dondurulması tekniği de çeşitli ırkların genetik materyallerinin uzun süreli saklanması ve transportunu kolaylaştıran ve rodent ırklarının muhafazasındaki maliyeti azaltan önemli bir biyotekniktir $(5,9)$. Spermanın kısa süreli ve uzun süreli saklanması tekniği pek çok memeli türünde kullanılıyor olmasına karşın bazı rodent türlerinde zorluklar bulunmaktadır (44). Rodent türlerinden fare ve rat spermatozoasının birbirine benzer özelliklerinin bulunmasına rağmen rat 
spermatozoasının mekanik strese duyarlılığının ve membran geçirgenliğinin farklı olması nedeniyle farelerde uygulanan sperma saklama protokolleri ratlara adapte edilememiştir (36). Rat spermatozoasının uzun bir kuyruğa sahip olması, baş yapısındaki ve membran lipid kompozisyonundaki farklılık soğuk şokuna karşı aşırı duyarlı olmasına yol açmaktadır $(15,20,22)$. Bu sebeplerden dolayı kabul edilebilir ve tekrarlanabilir rat spermatozoa saklama protokolü bulunmamaktadır (45). Spermanın dondurularak saklanması tekniği, spermatolojik parametrelerde geri dönüşümsüz hasarlara ve sonuçta fertilizasyon kapasitesinde azalmaya yol açtığından ratlarda kullanımı sınırlıdır (11). Spermanın soğutulması ve dondurularak saklanması sırasında oksidatif stress oluşmaktadır. Oluşan oksidatif stres etkisiyle aşırı üretilen reaktif oksijen türleri (ROS) de spermatozoa plazma membranlarında yağ asitleri ve fosfolipitlerde lipid peroksidasyona yol açarak kalıcı hasarlar oluşturmaktadır $(13,24)$. Spermatozoa ve seminal plazmada bulunan antioksidanlar ile hücre kendi yapısını oksidatif strese karşı korumaya çalışmaktadır (24). Ancak bu koruma spermatozoa yapısına bağlı olarak sınırlı olduğundan spermanın saklanması sırasında sulandırıcılara antioksidan ilaveleri yapılmaktadır $(3,7)$. Rat spermasında da başarılı saklama protokollerinin geliştirilmesi amacıyla yapılmış pek çok araştırma bulunmaktadır $(9,19,20,21)$. Rat epididimal spermatozoasında kısa süreli saklama çalışmalarının bulunmasına rağmen antioksidan madde olan karnitinin kullanıldığı ve farklı saklama sıcaklık derecelerinin test edildiği bir çalışma bulunmamaktadır. Bu çalışmanın amacı; ratlarda epididimal spermanın kısa süreli saklanmasında farklı sıcaklık dereceleri ve sperma sulandırıcısına katılan karnitinin spermatolojik parametreler üzerine etkilerini belirlemektir.

\section{Gereç ve Yöntem}

\section{Hayvan Materyali}

Bu çalışma, Erciyes Üniversitesi Hayvan Deneyleri Yerel Etik Kurulu (No: 15/137) tarafından onaylanmış olup Erciyes Üniversitesi Deneysel Araştırmalar Uygulama ve Araştırma Merkezi'nde yürütülmüştür. Sperma donörü olarak 10 adet 8-10 haftalık, 200-250 $\mathrm{g}$ ağırlıklarında Wistar-Albino erişkin rat kullanıldı. Çalışma, ergin erkek ratların epididimal spermaları üzerinde yürütüldü.

\section{Örnek Toplama ve Epididimal Spermanın Sulandı- rılması}

Çalışmada kullanılacak olan ratlardan ketamin/ ksilazin anestezisi altında, testis üreme organı dışarıya alınıp yağ dokularından arındırıldıktan sonra epididimis yapısı ayırdedildi. Sağ ve sol kauda epididimisler petri kutusu içerisindeki $1 \mathrm{ml}$ fizyolojik tuzlu suda (\% 0.9'luk $\mathrm{NaCl}$ ) bistüri ve makas yardımıyla iyice parçalanarak epididimal dokudaki spermatozoonların sıvıya geçmesi sağlandı. Epididimal spermanın sulandırılması amacıyla Tris buffer solüsyonu [Trisma base (T6066, Sigma-Aldrich, Co) $3.63 \mathrm{~g}$, glukoz 0.50 $\mathrm{g}$, sitrik asit $1.99 \mathrm{~g}$ ve distile su $100 \mathrm{ml} \mathrm{pH} 7$ ye ayarlanmıştır] hazırlandı $(22,23)$. Epididimal sperma numuneleri 4 ayrı gruba ayrılarak final konsantrasyonu $1-3 \times 10^{7} / \mathrm{mL}$ spermatozoa olacak şekilde tris sulandırıcı (T) ve 2 mM karnitin (C0283, Sigma-Aldrich, Co) katılmış tris sulandırıcısıyla (TC) sulandırılarak 4 ${ }^{\circ} \mathrm{C}$ de (T ve TC grubu) ve $37{ }^{\circ} \mathrm{C}$ de (T ve TC grubu) olmak üzere 5 farklı sürede $(0,6,12,24,48$ saat) bekletildi. Tüm gruplar beş farklı süre sonunda motilite ve anormal spermatozoa oranı gibi spermatolojik yönden analiz edildi.

\section{Spermatolojik Muayeneler}

Spermatozoa motilitesi: Belirtilen sürelerin sonunda sulandırıımış sperma örneklerinden küçük bir damla lam üzerine alınıp üzerine lamel kapatılarak ısıtma tablası $37{ }^{\circ} \mathrm{C}$ 'ye ayarlanmış mikroskobun 400 'lük büyütmesinde subjektif yolla motilite oranı belirlendi. Motilite analizleri üç farklı mikroskobik saha incelenerek yapıldı. Bu üç farklı sahanın ortalama değerleri yüzde motilite oranı olarak hesaplandı (37).

Anormal spermatozoon oran: Tüm deney gruplarında beş farklı saklama süresinin sonunda anormal spermatozoa oranının belirlenmesi amacıyla; temiz, kuru ve önceden ısıtılmış $\left(37^{\circ} \mathrm{C}\right)$ bir lama bir damla sperma numunesi ve birkaç damla Eozin-Nigrozin (1.67 g eozin, $10 \mathrm{~g}$ nigrozin, $2.9 \mathrm{~g}$ sodyum sitrat ve $100 \mathrm{ml}$ distile su) karışımı boya damlatılarak bir lam yardımıyla karıştırılıp homojen hale getirildi. Daha sonra bu sperma-boya karışımından ince frotiler çekilerek çok kısa sürede kuruması sağlandı. Kurutma işleminin ardından frotiler mikroskobun 400'lük büyütmesinde incelendi. Bir frotide toplam 300 spermatozoon incelenerek baş, kuyruk ve toplam anormal spermatozoon oranı yüzde olarak ifade edildi (39).

\section{İstatistikî Analizler}

Deneysel çalışmalar $10 \mathrm{kez}$ tekrar edildi. $4{ }^{\circ} \mathrm{C}$ ve 37 ${ }^{\circ} \mathrm{C}$ gibi iki faklı sıcaklıklarda saklanan Tris ve Tris+Karnitin grupları arasındaki farklığın önem kontrolünü karşılaştırmak için Mann Whitney $U$ testi ile 0., 6., 12., 24., 48. saatler arasındaki farklıı̆ı̆ı önem kontrolünde Friedman testi, ikili karşılaştırmalarda ise Wilcoxon testi kullanıldı. İstatistik analizler IBM SPSS 22 programı ile yapıldı.

\section{Bulgular}

İki farklı sıcaklık derecesinde $\left(4^{\circ} \mathrm{C}\right.$ ve $\left.37^{\circ} \mathrm{C}\right) \mathrm{kısa}$ süreli saklanan rat epididimal spermatozoa motilitesi üzerine karnitinin etkileri Tablo $1^{\prime}$ de gösterildi. $4{ }^{\circ} \mathrm{C}$ de saklanan rat spermasında, T ve TC gruplarında; 0 . ve 6 . saatte kaydedilen motilite oranları 48 . saattekiyle kıyaslandığında istatistiki açıdan ciddi bir düşme kaydedildi $(P<0.001)$. Rat epididimal spermasının 37 
Tablo 1. İki farklı sıcaklık derecesinde $\left(4^{\circ} \mathrm{C}\right.$ ve $\left.37^{\circ} \mathrm{C}\right)$ kısa süreli saklanan rat epididimal spermatozoa motilite oranı (\%) üzerine karnitinin etkileri

\begin{tabular}{|c|c|c|c|c|c|c|c|c|}
\hline \multicolumn{8}{|c|}{ Saat [Medyan (\%25-\%75)] } & \multirow{2}{*}{$\begin{array}{l}\text { P değeri } \\
\text { (Friedman } \\
\text { test) }\end{array}$} \\
\hline $\begin{array}{c}\text { Sıcak- } \\
\text { lık }\end{array}$ & Grup & $\mathbf{N}$ & 0. saat & 6. saat & 12. saat & 24. saat & 48. saat & \\
\hline \multirow{2}{*}{$4^{\circ} \mathrm{C}$} & $\begin{array}{l}\text { Tris } \\
\text { (T) }\end{array}$ & 10 & $\begin{array}{c}78^{\mathrm{a}} \\
(70.8-80.8)\end{array}$ & $\begin{array}{c}30^{\mathrm{a}} \\
(27.9-35.0)\end{array}$ & $\begin{array}{c}20.8^{\mathrm{ab}} \\
(20.0-25.8)\end{array}$ & $\begin{array}{c}11.0^{\mathrm{bc}} \\
(10.0-12.0)\end{array}$ & $\begin{array}{c}5.0^{c} \\
(4.0-5.0)\end{array}$ & $<0.001$ \\
\hline & $\begin{array}{c}\text { Tris+Karnitin } \\
\text { (TC) }\end{array}$ & 10 & $\begin{array}{c}75.5^{\mathrm{a}} \\
(72.5-80.7)\end{array}$ & $\begin{array}{c}60.5^{\mathrm{ab}} \\
(55.0-65.0)\end{array}$ & $\begin{array}{c}43.3^{\mathrm{b}} \\
(38.8-46.7)\end{array}$ & $\begin{array}{c}20.0^{\text {bc }} \\
(18.8-21.5)\end{array}$ & $\begin{array}{c}10.0^{c} \\
(7.8-10.0)\end{array}$ & $<0.001$ \\
\hline \multicolumn{3}{|c|}{ P değeri (Mann Whitney U test) } & 0.912 & $<0.001$ & $<0.001$ & $<0.001$ & $<0.001$ & \\
\hline \multirow{2}{*}{$37^{\circ} \mathrm{C}$} & $\begin{array}{l}\text { Tris } \\
(T)\end{array}$ & 10 & $\begin{array}{c}80.0^{\mathrm{a}} \\
(70.0-80.0)\end{array}$ & $\begin{array}{c}20.0^{\mathrm{ab}} \\
(19.6-21.0)\end{array}$ & $\begin{array}{c}13.3^{\mathrm{bc}} \\
(10.0-15.0)\end{array}$ & $\begin{array}{l}6.0^{\mathrm{bc}} \\
(5.0-8)\end{array}$ & $\begin{array}{c}4.0^{c} \\
(0.0-5.0)\end{array}$ & $<0.001$ \\
\hline & $\begin{array}{l}\text { Tris+Karnitin } \\
\text { (TC) }\end{array}$ & 10 & $\begin{array}{c}75.0^{\mathrm{a}} \\
(70.0-80.0)\end{array}$ & $\begin{array}{c}40.0^{\mathrm{ab}} \\
(38,3-45.0)\end{array}$ & $\begin{array}{c}30.0^{\mathrm{b}} \\
(28.7-31.6)\end{array}$ & $\begin{array}{c}10.0^{\mathrm{bc}} \\
(10.0-11.7)\end{array}$ & $\begin{array}{c}5.5^{c} \\
(5.0-7.8)\end{array}$ & $<0.001$ \\
\hline \multicolumn{3}{|c|}{ P değeri (Mann Whitney U test) } & 0.853 & $<0.001$ & $<0.001$ & $<0.001$ & 0.003 & \\
\hline
\end{tabular}

a,b,c: Aynı satırda farklı harf taşıyan gruplar arasındaki fark istatistiksel olarak önemlidir (Friedman Test). Sütunlar arası gruplarda önemlilik Mann Whitney U test sonuçlarına göre değerlendirildi.

Tablo 2. İki farklı sıcaklık derecesinde $\left(4^{\circ} \mathrm{C}\right.$ ve $\left.37^{\circ} \mathrm{C}\right)$ kısa süreli saklanan rat epididimal spermatozoa baş bölge anomali oranı (\%) üzerine karnitinin etkileri

\begin{tabular}{|c|c|c|c|c|c|c|c|c|}
\hline \multicolumn{8}{|c|}{ Saat [Medyan (\%25-\%75)] } & \multirow{2}{*}{$\begin{array}{c}\text { P değeri } \\
\text { (Friedma } \\
\text { n test) }\end{array}$} \\
\hline Sıcaklık & Grup & $\mathbf{N}$ & 0 . saat & 6. saat & 12. saat & 24. saat & 48. saat & \\
\hline \multirow{2}{*}{$4^{\circ} \mathrm{C}$} & $\begin{array}{l}\text { Tris } \\
\text { (T) }\end{array}$ & 10 & $\begin{array}{c}3.0^{\mathrm{a}} \\
(1.8-3.3)\end{array}$ & $\begin{array}{c}4.0^{\mathrm{a}} \\
(3.0-4.3)\end{array}$ & $\begin{array}{c}6.0^{\mathrm{ab}} \\
(6.0-7.0)\end{array}$ & $\begin{array}{c}13.0^{\mathrm{bc}} \\
(11-14.3)\end{array}$ & $\begin{array}{c}23.0^{\mathrm{C}} \\
(21.8-26)\end{array}$ & $<0.001$ \\
\hline & $\begin{array}{l}\text { Tris+Karnitin } \\
\text { (TC) }\end{array}$ & 10 & $\begin{array}{c}2.5^{\mathrm{a}} \\
(1.8-3.3)\end{array}$ & $\begin{array}{c}3.0^{\mathrm{a}} \\
(2-3.3)\end{array}$ & $\begin{array}{c}5.0^{\mathrm{ab}} \\
(4.0-6.0)\end{array}$ & $\begin{array}{c}14.0^{\mathrm{bc}} \\
(12.8-15.0)\end{array}$ & $\begin{array}{c}21.0^{c} \\
(20-22.3)\end{array}$ & $<0.001$ \\
\hline \multicolumn{3}{|c|}{$P$ değeri (Mann Whitney $U$ test) } & 0.505 & 0.056 & 0.010 & 0.233 & 0.032 & \\
\hline \multirow{2}{*}{$37^{\circ} \mathrm{C}$} & $\begin{array}{l}\text { Tris } \\
\text { (T) }\end{array}$ & 10 & $\begin{array}{c}2.0^{\mathrm{a}} \\
(2.0-3.0)\end{array}$ & $\begin{array}{c}7.0^{\mathrm{ab}} \\
(5.8-7.5)\end{array}$ & $\begin{array}{c}22.5^{\mathrm{bc}} \\
(21.0-24.0)\end{array}$ & $\begin{array}{c}35.0^{\text {cd }} \\
(34.0-36.0)\end{array}$ & $\begin{array}{c}38.0^{\mathrm{d}} \\
(37.0-39.3)\end{array}$ & $<0.001$ \\
\hline & $\begin{array}{l}\text { Tris+Karnitin } \\
\text { (TC) }\end{array}$ & 10 & $\begin{array}{c}2.0^{\mathrm{a}} \\
(1.0-3.3)\end{array}$ & $\begin{array}{c}3.5^{\mathrm{a}} \\
(2.8-4.3)\end{array}$ & $\begin{array}{c}13.0^{\mathrm{ab}} \\
(11.8-13.3)\end{array}$ & $\begin{array}{c}24.5^{\mathrm{b}} \\
(24-25.3)\end{array}$ & $\begin{array}{c}27.5^{\mathrm{b}} \\
(24.5-29.3)\end{array}$ & $<0.001$ \\
\hline \multicolumn{3}{|c|}{ P değeri (Mann Whitney $U$ test) } & 0.751 & $<0.001$ & $<0.001$ & $<0.001$ & $<0.001$ & \\
\hline
\end{tabular}

a,b,c,d: Aynı satırda farklı harf taşıyan gruplar arasındaki fark istatistiksel olarak önemlidir (Friedman Test). Sütunlar arası gruplarda önemlilik Mann Whitney U test sonuçlarına göre değerlendirildi.

Tablo 3. İki farklı sıcaklık derecesinde $\left(4^{\circ} \mathrm{C}\right.$ ve $\left.37^{\circ} \mathrm{C}\right)$ kısa süreli saklanan rat epididimal spermatozoa kuyruk anomali oranı (\%) üzerine karnitinin etkileri

\begin{tabular}{|c|c|c|c|c|c|c|c|c|}
\hline \multicolumn{8}{|c|}{ Saat [Medyan (\%25-\%75)] } & \multirow{2}{*}{$\begin{array}{c}\text { P değeri } \\
\text { (Friedman } \\
\text { test) }\end{array}$} \\
\hline $\begin{array}{l}\text { Sıcak- } \\
\text { lık }\end{array}$ & Grup & $\mathbf{N}$ & 0. saat & 6. saat & 12. saat & 24. saat & 48. saat & \\
\hline \multirow[b]{2}{*}{$4^{\circ} \mathrm{C}$} & $\begin{array}{l}\text { Tris } \\
\text { (T) }\end{array}$ & 10 & $\begin{array}{c}3.0^{\mathrm{a}} \\
(1.8-4.3)\end{array}$ & $\begin{array}{c}7.0^{\mathrm{ab}} \\
(6.0-7.0)\end{array}$ & $\begin{array}{c}9.0^{\mathrm{ab}} \\
(8.0-9.3)\end{array}$ & $\begin{array}{c}12.8^{\mathrm{bc}} \\
(14.0-15.0)\end{array}$ & $\begin{array}{c}25.0^{\mathrm{C}} \\
(20.5-26.3)\end{array}$ & $<0.001$ \\
\hline & $\begin{array}{c}\text { Tris+ } \\
\text { Karnitin } \\
\text { (TC) }\end{array}$ & 10 & $\begin{array}{l}3.0^{\mathrm{a}} \\
(2-4)\end{array}$ & $\begin{array}{c}4.0^{\mathrm{ab}} \\
(3.75-5)\end{array}$ & $\begin{array}{c}7.5^{\mathrm{b}} \\
(6.75-9.25)\end{array}$ & $\begin{array}{c}9.5^{b} \\
(9-10.25)\end{array}$ & $\begin{array}{c}14.0^{\mathrm{c}} \\
(13-15)\end{array}$ & $<0.001$ \\
\hline \multicolumn{2}{|c|}{$\begin{array}{c}\text { P değeri } \\
\text { (Mann Whitney U test) }\end{array}$} & & 0.786 & $<0.001$ & 0.150 & $<0.001$ & $<0.001$ & \\
\hline \multirow[b]{2}{*}{$37^{\circ} \mathrm{C}$} & $\begin{array}{l}\text { Tris } \\
\text { (T) }\end{array}$ & 10 & $\begin{array}{c}3.0^{\mathrm{a}} \\
(1.8-4.0)\end{array}$ & $\begin{array}{c}8.0^{\mathrm{ab}} \\
(6.8-9.0)\end{array}$ & $\begin{array}{c}11.0^{\mathrm{bc}} \\
(10.0-13.0)\end{array}$ & $\begin{array}{c}24.0^{c} \\
(24.0-25.0)\end{array}$ & $\begin{array}{c}26.0^{\mathrm{c}} \\
(24.8-29.3)\end{array}$ & $<0.001$ \\
\hline & $\begin{array}{c}\text { Tris+ } \\
\text { Karnitin } \\
\text { (TC) }\end{array}$ & 10 & $\begin{array}{c}3.5^{\mathrm{a}} \\
(2.0-4.0)\end{array}$ & $\begin{array}{c}6.5^{\mathrm{ab}} \\
(5.0-7.0)\end{array}$ & $\begin{array}{c}8.0^{\mathrm{ab}} \\
(7.0-9.0)\end{array}$ & $\begin{array}{c}13.0^{\mathrm{bc}} \\
(11.8-14.0)\end{array}$ & $\begin{array}{c}22.5^{c} \\
(20.8-23.3)\end{array}$ & $<0.001$ \\
\hline \multicolumn{2}{|c|}{$\begin{array}{c}\text { P değeri } \\
\text { (Mann Whitney U test) }\end{array}$} & & 0.432 & 0.017 & $<0.001$ & $<0.001$ & 0.002 & \\
\hline
\end{tabular}

a,b,c. Aynı satırda farklı harf taşıyan gruplar arasındaki fark istatistiksel olarak önemlidir (Friedman Test). Sütunlar arası gruplarda önemlilik Mann Whitney U test sonuçlarına göre değerlendirildi. 
Tablo 4. İki farklı sıcaklık derecesinde $\left(4^{\circ} \mathrm{C}\right.$ ve $\left.37^{\circ} \mathrm{C}\right)$ kısa süreli saklanan rat epididimal spermatozoa toplam morfolojik anomali oranı (\%) üzerine karnitinin etkileri.

\begin{tabular}{|c|c|c|c|c|c|c|c|c|}
\hline \multicolumn{8}{|c|}{ Saat [Medyan (\%25-\%75)] } & \multirow{2}{*}{$\begin{array}{l}P \text { değeri } \\
\text { (Friedman } \\
\text { test) }\end{array}$} \\
\hline Sıcaklık & Grup & $\mathbf{N}$ & 0. saat & 6. saat & 12. saat & 24. saat & 48. saat & \\
\hline \multirow[b]{2}{*}{$4^{\circ} \mathrm{C}$} & $\begin{array}{l}\text { Tris } \\
(\mathrm{T})\end{array}$ & 10 & $\begin{array}{c}6.0^{\mathrm{a}} \\
(4.0-7.3)\end{array}$ & $\begin{array}{c}10.5^{\mathrm{ab}} \\
(9.0-11.3)\end{array}$ & $\begin{array}{c}15.0^{\mathrm{bc}} \\
(14.0-16.3)\end{array}$ & $\begin{array}{c}26.5^{\mathrm{cd}} \\
(25.0-28.5)\end{array}$ & $\begin{array}{c}47.0^{\mathrm{d}} \\
(45.5-49.5)\end{array}$ & $<0.001$ \\
\hline & $\begin{array}{c}\text { Tris+ } \\
\text { Karnitin } \\
\text { (TC) }\end{array}$ & 10 & $\begin{array}{c}5.5^{\mathrm{a}} \\
(4.0-7.0)\end{array}$ & $\begin{array}{c}7.0^{\mathrm{a}} \\
(6.0-8.0)\end{array}$ & $\begin{array}{c}12.5^{\mathrm{ab}} \\
(12.0-14.0)\end{array}$ & $\begin{array}{c}23.0^{\mathrm{bc}} \\
(22.3-25.3)\end{array}$ & $\begin{array}{c}35.0^{c} \\
(34.0-36.3)\end{array}$ & $<0001$ \\
\hline \multicolumn{2}{|c|}{$\begin{array}{l}\text { P değeri } \\
\text { (Mann Whitney U test) }\end{array}$} & & 0.671 & $<0.001$ & 0.014 & 0.005 & $<0.001$ & \\
\hline \multirow[b]{2}{*}{$37^{\circ} \mathrm{C}$} & $\begin{array}{l}\text { Tris } \\
(\mathrm{T})\end{array}$ & 10 & $\begin{array}{c}5.5^{\mathrm{a}} \\
(4.5-6.3)\end{array}$ & $\begin{array}{c}14.0^{\mathrm{ab}} \\
(13.0-17.0)\end{array}$ & $\begin{array}{c}34.0^{\mathrm{bc}} \\
(32.8-34.5)\end{array}$ & $\begin{array}{c}59.0^{\mathrm{c}} \\
(58.8-60.0)\end{array}$ & $\begin{array}{c}64.0^{\mathrm{c}} \\
(61.3-67.5)\end{array}$ & $<0.001$ \\
\hline & $\begin{array}{c}\text { Tris+ } \\
\text { Karnitin } \\
\text { (TC) }\end{array}$ & 10 & $\begin{array}{c}6.0^{\mathrm{a}} \\
(4.8-6.3)\end{array}$ & $\begin{array}{c}10.0^{\mathrm{ab}} \\
(8.0-11.0)\end{array}$ & $\begin{array}{c}20.5^{\mathrm{bc}} \\
(19.8-22.0)\end{array}$ & $\begin{array}{c}37.5^{\mathrm{cd}} \\
(37.0-38.0)\end{array}$ & $\begin{array}{c}49.0^{d} \\
(46.8-53.0)\end{array}$ & $<0.001$ \\
\hline \multicolumn{3}{|c|}{$\begin{array}{l}\text { P değeri } \\
\text { (Mann Whitney U test) }\end{array}$} & 0.726 & $<0.001$ & $<0.001$ & $<0.001$ & $<0.001$ & \\
\hline
\end{tabular}

${ }^{\circ} \mathrm{C}$ de $\mathrm{T}$ ve TC gruplarının her ikisinde de ilerleyen saklama süresi sonunda motilite oranında ciddi düşmeler kaydedildi $(\mathrm{P}<0.001)$. T ve TC grupları karşılaştırıldığında, $4{ }^{\circ} \mathrm{C}$ de TC grubunda 6 . saatten itibaren 48. saate kadar ilerleyen farklı saklama süreleri boyunca $T$ grubuna kıyasla istatistiki açıdan farklı ve yüksek bir motilite oranı gözlendi $(P<0.001) .37{ }^{\circ} \mathrm{C}$ 'de $\mathrm{T}$ ve TC grupları kendi aralarında kıyaslandığında, her iki grupta da 0 . saatte kaydedilen motilite oranı istatistiki olarak benzer iken ( $P>0.05)$, diğer saatlerde TC grubunda kaydedilen motilite oranları T grubuna kıyasla istatistiki açıdan daha yüksek bulundu $(\mathrm{P}<0.01$; $\mathrm{P}<0.001)$. Çalışmada, $4^{\circ} \mathrm{C}$ de karnitin katılan TC grubunda diğer tüm gruplara kıyasla daha yüksek motilite oranı kaydedildi. İki farklı sıcaklık derecesinde $\left(4{ }^{\circ} \mathrm{C}\right.$ ve $\left.37^{\circ} \mathrm{C}\right)$ kısa süreli saklanan rat epididimal sperm baş bölge anomalisi üzerine karnitinin etkileri Tablo 2' de gösterildi. Rat epididimal sperması $4{ }^{\circ} \mathrm{C}$ ve $37{ }^{\circ} \mathrm{C}$ 'de T ve TC gruplarının her ikisinde de 48 . saate doğru ilerleyen saklama süresince spermatozoa baş anomali oranında istatistiki açıdan önemli bir artış gözlendi $(\mathrm{P}<0.001) .4{ }^{\circ} \mathrm{C}$ ' de 12 . ve 48. saatlerde, $37^{\circ} \mathrm{C}$ 'de 6., 12., 24. ve 48 . saatleri arasında baş anomalisi oranı TC grubunda istatistiki olarak daha düşük kaydedildi. İki farklı sıcaklık derecesinde $\left(4^{\circ} \mathrm{C}\right.$ ve $\left.37^{\circ} \mathrm{C}\right)$ kısa süreli saklanan rat epididimal sperm kuyruk anomalisi üzerine karnitinin etkileri Tablo 3' de gösterildi. Her iki saklama sıcaklık derecelerinde saatlere göre değerlendirme yapıldığında; T ve TC gruplarının her ikisinde de saklama periyodunun ilerlemesiyle kuyruk anomalisi oranında önemli derecede artış gözlendi $(P<0.001) .4{ }^{\circ} \mathrm{C}$ de saklanan TC grubunda 6., 24., ve 48 . saatlerde, 37 ${ }^{\circ}$ Cde saklanan TC grubunda da 6.,12., 24., ve 48. saatlerde $\mathrm{T}$ grubuna kıyasla istatistiki olarak daha düşük anomali oranı kaydedildi. İki farklı sıcaklık derecesinde kısa süreli saklanan rat epididimal spermatozoa toplam morfolojik bozukluklar üzerine karnitinin etkileri Tablo 4' de gösterildi. Saatlere göre değerlendirme yapıldığında T ve TC gruplarında ilerleyen zamanla beraber spermatozoanın toplam anomali oranında istatistiki açıdan anlamlı bir artış saptandı $(\mathrm{P}<0.001)$. T ve TC grupları kendi aralarında karşılaştırıldığında; $4{ }^{\circ} \mathrm{C}$ ve $37^{\circ} \mathrm{C}$ ' de yapılan kısa süreli saklamanın 6.,12.,24.,ve 48.saatlerinde TC grubunda istatistiki olarak daha düşük toplam morfolojik anomali oranı kaydedildi, $4{ }^{\circ} \mathrm{C}$ ' nin morfolojik yapıyı korumada $37^{\circ} \mathrm{C}$ ' ye kıyasla daha etkin olduğu saptandı.

\section{Tartışma ve Sonuç}

Spermanın saklanmasında iki önemli prosedür kullanılmaktadır. Bunlardan biri kısa süreli saklama diğeri ise uzun süreli dondurularak saklamadır. Sperma saklama prosedürlerinin ortak amacı saklama süresi boyunca spermatozoa canlılığında devamlılığının sağlanmasıdır. Spermatozoanın canlılığını koruyan ve devamlılığını sağlayan spermanın uygun sulandırıcılarla sulandırılması ve saklama sıcaklığının düşürülmesidir. Bu durum, spermatozoa metabolizmasının yavaşlamasını, fertil yaşam süresinin uzatılmasını ve sperma saklama protokolünün başarıya ulaşmasını sağlamaktadır $(29,47)$.

Yapılan bu çalışmada, rat epididimal spermasının kısa süreli saklanması süresince ilerleyen zamana bağlı olarak spermatolojik parametrelerden motilite ve anormal spermatozoa oranında şekillenen değişimler ve bu değişimler üzerine karnitinin etkileri gösterildi.

Pek çok rat ırkının spermasının dondurulmasına iliş- 
kin çalışmalar bulunmakla birlikte bu çalışmaların farklı araştırma grubu ve laboratuvarlarında tekrarlanmalarında sıkıntıların olduğu bildirilmektedir (46).

Yapılan çalışmada, saklama saatlerine göre değerlendirme yapıldığında T ve TC gruplarında iki farklı saklama sıcaklığında da saklama süresinin 0 . saatinden 48. saate doğru ilerlemesiyle beraber motilite oranında ciddi bir düşme gözlendi. Bu durum, rat spermatozoonunun ebatlarına, non spherik şekillerine bağlı olarak soğutma işlemlerinde zorlukların olmasına ve hücrelerin biyofiziksel cevaplarının farklılık göstermesine bağlanmaktadır (18). Rodent sperm karakterleri memeli spermatozoasından membran lipid içeriği, kompozisyonu ve uzun kuyruk yapısındaki farklılığa bağlı olarak değişiklik göstermektedir $(29,30)$. Bu nedenle, rat spermi santrifügasyon, $\mathrm{pH}$, viskosite, osmotik basınç gibi çevresel değişimlere de oldukça duyarlıdır $(31,34,36,41)$. Soğutmayla beraber şekillenen soğuk şokunun etkisiyle rat spermatozoasında geri dönüşümsüz hasarlar oluşmakta, membran kolesterol içeriklerinde farklılık meydana gelmekte ve sonuç olarak membran akışkanlığı ve su geçirgenliğini değiştirmektedir (19). Memeli spermatozoası metabolik ihtiyaçları için gereken enerjiyi hem mitokondrial oksidatif respirasyon hem de glikolizis sayesinde sağlamaktadır. Bu enerjinin, yeterli ve sürekli sağlanması flagellumun hareketi yani spermatozoa motilitesi için gereklidir (12). Bu nedenle sperma sulandırıcılarına enerji sağlayıcı katkı maddelerinin eklenmesi spermatozoa fonksiyonları için gereken ATP sentezlenmesinde önemli olduğu ve dondurmaçözdürme sonu soğuk hasarına karşı koruyucu etkisinin olduğu bildirilmektedir (46). Rat spermatozoasının membran ve morfolojik yapısında saklama süresinin ilerlemesiyle beraber gözlenen bozukluklar motilite kaybını da indüklemektedir. Çünkü spermatozoonun orta kısmında oksidatif fosforilasyona bağlı olarak ATP sentezlenmesinde görevli aksonemlerce çevrelenmiş mitokondrialar bulunmaktadır. Üretilen bu enerji de sperm metabolizması ve sperm motilitesinde kullanılmaktadır (38).

Çalışmamızda rat epididimal spermatozoasında gözlenen baş ve kuyruk bölge morfolojik anomalileri mitokondriadaki hasara da yol açabileceğinden motilite kaybıyla karşımıza çıkabilmektedir. Spermanın soğutulması safhasında oluşan soğuk şoku etkisiyle motilitedeki kayıplar rat $(34,41)$, tavşan (34) ve koçlarda (14) gösterilmiştir. Rat spermatozoası ve testis dokusunun dondurulabilirliği ve çözüm sonu yaşama gücü ile reprodüktif yeteneği de oldukça kısıtlıdır (30). ÇaIışmanın motilite sonuçlarına göre, her iki saklama sıcaklığında da $\left(4^{\circ} \mathrm{C}\right.$ ve $\left.37^{\circ} \mathrm{C}\right)$ saklama süresinin 48 . saate doğru ilerlemesiyle beraber önemli derecede motilite kaybının oluştuğu, $4{ }^{\circ} \mathrm{C}$ 'nin $37^{\circ} \mathrm{C}$ 'ye kıyasla motiliteyi daha iyi koruduğu söylenebilmektedir. Bu durum, spermatozoanın soğutulmasıyla beraber metabolizmasını yavaşlatarak motilite ve fertil yaşam süresinin uzatmasına bağlanmaktadır $(29,47)$. Çalış- mamızın motilite sonuçları, Varışlı ve ark.'nın (43) çalışmaları sonucunda elde ettikleri motilite sonuçlarına benzerlik göstermesine karşın $4{ }^{\circ} \mathrm{C}$ nin diğer saklama derecelerine kıyasla daha hasar verici buldukları sonucundan farklılık göstermektedir. Bu durum, çalışmamızda kullanılan rat ırkının farklı oluşuna ve sulandırıcıda kullandığımız karnitinin olumlu etkisinin gözlenmesine bağlanmıştır. Çalışmamızda, her iki saklama sıcaklığında da karnitin katılan gruplarda sadece trisle sulandırılan gruplara kıyasla motilitenin önemli derecede iyi korunduğu saptanmıştır. Bu durum, karnitinin önemli bir antioksidan madde olmasına ve saklama süresince şekillenen lipid peroksidasyona karşı antioksidatif özellik göstermesine bağlanmıştır. Spermanın in vitro maniplasyonu süresince soğutma ve dondurma gibi işlemlere maruz kalması spermada reaktif oksijen türlerinin (ROS) aşırı üretilmesine yol açmaktadır (6). Reaktif oksijen türleri oksijen metabolizmasının bir ürünü olarak karşımıza çıkar ve spermatozoada plazma membranı ve mitokondriaları düzeyinde oluşur. Sonuncu mekanizma, spermatozoadaki ROS'un temel kaynağıdır. Çünkü, spermatozoada motilite için gerekli enerjiyi sağlayabilmek amacıyla çok sayıda mitokondria bulunmaktadır. Spermada spermatozoa fonksiyon bozukluklarında ROS düzeyi önemli derecede artmaktadır bu da mitokondrial fonksiyonu bozarak motilite gibi tüm spermatozoa fonksiyonlarını geri dönüşümsüz hasara uğratmaktadır $(1,21)$. Aşırı ROS üretimini dengede tutmak amacıyla seminal plazma ve spermatozoada doğal antioksidanlar bulunmaktadır (35). Ancak kısıtlı miktarlarına bağlı olarak sperma sulandırıcılarına antioksidan ilaveleri yaygın şekilde yapılmaktadır $(3,16)$. Çalışmamızda karnitin kullanılmış gruplarda motilitenin sadece tris ile sulandırılan gruplara kıyasla daha iyi korunması da antioksidanların ROS oluşumunu engellemeleri ya da direkt yok etmeleri ile spermatozoa plazma membranındaki lipidlerin korunmasına ve dolayısıyla spermatozoa motilite ve canlılığının muhafazasını sağladığı bilgisiyle paralellik göstermektedir (26). Sarıözkan ve ark.'nın (34) kısa süreli saklamanın yapıldığı tavşan spermasında $0.5 \mathrm{mM}$ dozda karnitinin saklamanın 12. saatinde motilite, akrozomal ve membran bütünlüğünde önemli derecede koruma sağladığını bildirmişlerdir. Yaptığımız çalışmanın sonucu belirtilen çalışmanın sonuçlarıyla benzerlik göstermektedir. Ayrıca, karnitinin kullanıldığı, boğa spermanın dondurulması-çözdürülmesi sonrası motilite üzerine olumlu etkisinin gösterildiği çalışma ile de paralellik göstermektedir (8).

Yapılan çalışmada rat epididimal spermasının iki farkIı saklama sıcaklığında kısa süreli saklanmasında saklama süresinin ilerlemesiyle beraber baş, kuyruk ve toplam anormallik oranının artış gösterdiği, karnitin ilave edilen gruplarda sadece trisle sulandırılan gruplara kıyasla istatistikî açıdan önemli derecede koruyucu etki yaptığı ve $4{ }^{\circ} \mathrm{C}$ ' de normal morfolojik yapı bütünlüğünün $37^{\circ} \mathrm{C}$ ' ye kıyasla daha iyi korunduğu tes- 
pit edildi. Çalışmanın sonuçları, kısa süreli saklamada ilerleyen zamana bağlı olarak tavşanlarda (35) ve bizonlarda (23) motilite, canlılık ve normal morfolojiye sahip spermatozoa oranında ciddi kayıpların olduğu ve rat epididimal spermasının $4{ }^{\circ} \mathrm{C}$ de soğutulmasının akrozomal bütünlük üzerine zarar verici etkisi olmadığına dair çalışmaların sonuçlarıyla uyum göstermektedir (41).

Sonuç olarak, sperma soğutulması süresince şekillenen soğuk şoku nedeniyle spermatozoa membran yapısı ve ortamın ozmotik yapısı değişikliğe uğramaktadır. Bu değişiklikler, kısa süreli saklama süresince ilerleyen zamanın da etkisiyle spermatolojik özellikleri olumsuz etkilemektedir. Sperma sulandırıcılarına antioksidatif özelliğe sahip ajanların katılması spermatolojik özellikleri korumaktadır. Yapılan çalışmada $4{ }^{\circ} \mathrm{C}$ ve $37^{\circ} \mathrm{C}$ lerde kısa süreli saklama süresince ilerleyen zamana karşı rat spermatolojik parametrelerinden motilite oranında düşme, baş, kuyruk ve toplam spermatozoa morfolojik anomalilikler oranında artış olduğu ancak, $4{ }^{\circ} \mathrm{C}$ ' de muhafaza edilen ve karnitin ilave edilmiş gruplarda spermatolojik parametrelerin sadece trisle sulandırılan gruplara kıyasla daha iyi korunduğu tespit edilmiştir.

\section{Kaynaklar}

1. Agarwal A, Virk G, Ong C, Du Plessis SS. Effect of oxidative stress on male reproduction. World $\mathrm{J}$ Mens Health 2014; 32(1): 1-17.

2. Ağca $\mathrm{Y}$, Critser JK. Assisted reproductive technologies and genetic engineering in rats, Suckow MA, Weisbroth SH, Franklin CL. (eds). In: The Laboratory Rat. San Diego: Academic Press, 2005; pp.165-90.

3. Aitken RJ, Clarkson JS, Fishel S. Generation of reactive oxygen species, lipid peroxidation and human sperm function. Biol Reprod 1989; 41: 183 -97 .

4. Aitken RJ. Free radicals, lipid peroxidation and sperm function. Reprod Fertil Dev 1995; 7(4): 659 -68 .

5. Audrins P, Holden CA, McLachlan RI, Kovacs GT. Semen storage for special purposes at monash IVF from 1977 to 1997. Fertil Steril 1999; 72(1): 179-81.

6. Bailey JL, Bilodeau JF, Cormier N. Semen cryopreservation in domestic animals: a damaging and capacitating phenomenon. J Androl 2000; 21(1): 1 $-7$.

7. Beconi MT, Affranchino MA, Schang LM, Beorlegui NB. Influence of antioxidants on SOD activity in bovine sperm. Biochem Int 1991; 23(3): 54553.
8. Bucak MN, Tuncer PB, Sarı̈zkan S, Başpınar N, Taşpınar M, Çoyan K, Bilgili A, Akalın PP, Büyükleblebici S, Aydos S, Ilgaz S, Sunguroğlu A, Öztuna D. Effects of antioxidants on post-thawed bovine sperm and oxidative stress parameters: Antioxidants protect DNA integrity against cryodamage. Cryobiology 2010; 61(3): 248-53.

9. Buehr M, Hjorth JP, Hansen AK, Sandoe P. Genetically modified laboratory animals-what welfare problems do they face? J Appl Anim Welf Sci 2003; 6(4): 319-38.

10. Cardullo RA, Baltz JM. Metabolic regulation in mammalian sperm: Mitochondrial volume determines sperm length and flagellar beat frequency. Cell Motil Cytoskeleton 1991; 19(3): 180-8.

11. Charreau B, Tesson L, Soulillou JP, Pourcel C, Anegon I. Transgenesis in rats: Technical aspects and models. Transgenic Res 1996; 5(4): 223-34.

12. Cummins JM, Woodall PF. On mammalian sperm dimensions. J Reprod Fertil 1985; 75(1): 153-75.

13. Çaylak E. Hayvan ve bitkilerde oksidatif stres ile antioksidanlar. Tıp Araştırmaları Dergisi 2011; 9 (1): 73-83.

14. Çoyan K, Başpınar N, Bucak MN, Akalın PP, Ataman $M B$, Ömür $A D$, Güngör $S ̧$, Küçükgünay $S$, Özkalp B, Sarıözkan S. Influence of methionine and dithioerythritol on sperm motility, lipid peroxidation and antioxidant capacites during liquid storage of ram semen. Res Vet Sci 2010; 89(3): 426-31.

15. Devireddy RV, Swanlund DJ, Roberts KP, Bischof JC. Subzero Water permeability parameters of mouse spermatozoa in the presence of extracellularilce and cryoprotective agents. Biol Reprod 1999; 61(3): 764-75.

16. Gadea J, Garcia-Vazquez F, Matas C, Gardon JC, Canovas S, Gumbao D. Cooling and freezing of boar spermatozoa: supplementation of the freezing media with reduced glutathione preserves sperm function. J Androl 2005; 26(3): 396-404.

17. Gunasena KT, Villines PM, Critser ES, Critser JK. Live births after autologous transplant of cryopreserved mouse ovaries. Hum Reprod 1997; 12(1): 101-6.

18. Hagiwara M, Choi JH, Devireddy RV, Roberts KP, Wolkers WF, Makhlouf A, Bischof JC. Cellular biophysics during freezing of rat and mouse sperm predicts post-thaw motility. Biol Reprod 2009; 81(4): 700-6.

19. Hall JC, Hadley J, Doman T. Correlation between changes in rat sperm membrane lipid, protein and 
the membrane physical state during epididymal maturation. J Androl 1991; 12(1): 76-87.

20. Hammerstedt RH, Graham JK, Nolan JP. Cryopreservation of mammalian sperm: What we ask them to survive. J Androl 1990; 11(1): 73-88.

21. Henkel RR. Leukocytes and oxidative stress: Dilemma for sperm function and male fertility. Asian J Androl 2011; 13(1): 43-52.

22. Holt WV. Fundemental aspects of sperm cryobiology: the importance of species and individual differences. Theriogenology 2000; 53(1): 47-58.

23. Karunakaran M, Dhali A, Mech A, Khate K, Rajkhowa C, Mishra DP. Preservation of mithun (Bos frontalis) semen at refrigeration temperature. Anim Reprod Sci 2006; 101(3-4): 257-64.

24. Kim JG, Parthasarathy S. Oxidation and the spermatozoa. Semin Reprod Endocrinol 1998; 16(4): 235-9.

25. Landel CP. Archiving mouse strains by cryopreservation. Lab Anim (NY) 2005; 34: 50-7.

26. Lanzafame FM, La Vignera S, Vicari E, Calogero $A E$. Oxidative stress and medical antioxidant treatment in male infertility. Reprod Biomed Online 2009; 19(5): 638-59.

27. Lazar J, Moreno C, Jacob HJ, Kwitek AE. Impact of genomics on research in the rat. Genome Res 2005; 15: 1717-28.

28. Leibo SP, Songsasen N. Cryopreservation of gametes and embryos of non-domestic species. Theriogenology 2002; 57(1): 303-26.

29. Maxwell WM, Salamon S. Liquid storage of ram semen: A review. Reprod Fertil Dev 1993; 5(6): 613-38.

30. Mazur P, Leibo SP, Seidel GE. Cryopreservation of the germplasm of animals used in biological and medical research: Importance, impact, status and future directions. Biol Reprod 2008; 78(1): 212

31. Nakatsukasa E, Kashiwazaki N, Takizawa A, Shino M, Kitada K, Serikawa T, Hakamata Y, Kobayashi $E$, Takahashi R, Ueda M, Nakashima T, Nakagata N. Cryopreservation of spermatozoa from closed colonies and inbred spontaneous mutant and transgenic strains of rats. Comp Med 2003; 53(6): 639-41.

32. Parks JE, Lynch DV. Lipid composition and thermotropic behaviour of boar, bull, stallion and rooster sperm membranes. Cryobiology 1992; 29(2): 255-66.
33. Sarı̈zkan S, Bucak MN, Cantürk F, Özdamar S, Yay A, Tuncer PB, Özcan S, Sorgucu N, Caner Y. The effects of different sugars on motility, morphology and DNA damage during the liquid storage of rat epididymal sperm at $4{ }^{\circ} \mathrm{C}$. Cryobiology 2012; 65(2): 93-7.

34. Sarıözkan S, Özdamar S, Türk G, Cantürk F, Yay A. In vitro effects of L-carnitine and glutamine on motility, acrosomal abnormality, and plasma membrane integrity of rabbit sperm during liquidstorage. Cryobiology 2014; 68(3): 349-53.

35. Sharma RK, Agarwal A. Role of reactive oxygen species in male infertility. Urology 1996; 48(6): 835-50.

36. Si W, Benson JD, Men H, Critser JK. Osmotic tolerance limits and effects of cryoprotectants on the motility, plasma membrane integrity and acrosomal integrity of rat sperm. Cryobiology 2006; 53 (3): $336-48$

37. Sonmez M, Turk G, Yuce A. The effect of ascorbic acid supplementation on sperm quality, lipid peroxidation and testosterone levels of male wistar rats. Theriogenology 2005; 63(7): 2063-72.

38. Suarez SS, Marquez B, Harris TP, Schimenti JC Different regulatory systems operate in the midpiece and principal piece of the mammalian sperm flagellum. Soc Reprod Fertil Suppl 2007; 65: 331 4

39. Turk G, Ateşşahin A, Sönmez M. Lycopene protects against cyclosporine A-induced testicular toxicity in rats. Theriogenology $2007 ; 67(4)$ : 778 85.

40. Turk G, Ceribaşı AO, Sakin F, Sönmez M, Ateşşahin $A$. Antiperoxidative and anti-apoptotoic effects of lycopene and ellagic acid on crclophosphamide-induced testicular lipid peroxidation and apoptosis. Reprod Fertil Dev 2010; 22(4): 587-96.

41. Varışlı O, Uguz C, Agca C, Agca Y. Effect of chilling on the motility and acrosomal integrity of rat sperm in the presence of various extenders. J Am Assoc Lab Anim Sci 2009; 48(5): 499-505.

42. Varışlı O, Uguz C, Agca C, Agca Y. Various physical stres factors on rat sperm motility, integrity of acrosome, and plasma membrane. J Androl 2009 30(1): 75-86.

43. Varışlı Ö, Ağca C, Ağca Y. Short-term storage of rat sperm in the presence of various extenders. J Am Assoc Lab Anim Sci. 2013; 52(6): 732-7.

44. Verberckmoes S, Van Soom A, Dewulf J, De Pauw I, De Kruif A. Storage of fresh bovine semen in a diluent based on the ionic composition of 
cauda epididymal plasma. Reprod Dom Anim 2004; 39(6): 410-6.

45. Yamashiro H, Han YJ, Sugawara A, Tomioka I, Hoshino Y, Sato E. Freezability of rat epididymal sperm induced by raffinose in modified KrebsRinger bicarbonate (mKRB) based extender solution. Cryobiology 2007; 55(3): 285-94.

46. Yamashrio H, Sato E. Cryopreservation of rat sperm. Katkow I. ed. In: Current Frontiers in Cryopreservation. London: IntechOpen, 2012; pp. 165-78.

47. Yoshida M. Conservation of sperm: Current status and new trends. Anim Reprod Sci 2000; 60(61): 349-55. 